of inherited thrombophilia on venous thromboembolism in children: a systematic review and meta-analysis of observational studies. Circulation 2008;118:1373-1382.
8. Shatzel JJ, O'Donnell M, Olson SR, Kearney MR, Daughety MM, Hum J, Nguyen KP, DeLoughery TG. Venous thrombosis in unusual sites: A practical review for the hematologist. Eur J Haematol 2019;102:53-62.

\title{
A Successful Coronary Artery Bypass Operation with Intermittent Factor VIII Administration in a Hemophilia A Patient Who Was Admitted Due to Acute Myocardial Infarction: A Rare and Difficult Case
}

\author{
Akut Myokard Infarktüsü ile Başvuran Bir Hemofili A Hastasında Aralıklı Faktör VIII \\ Uygulamasılyla Başarı Sağlanabilen Koroner Arter Bypass Operasyonu: Nadir ve Zor Olgu
}

\author{
(D) Ulaş Serkan Topaloğlu1, (D) Rıfat Özmen², (D) Recep Civan Yüksel33, (D) Murat Çetin4, (D) Gülşah Akyol5 \\ ${ }^{1}$ Kayseri City Training and Research Hospital, Clinic of Internal Medicine, Kayseri, Turkey \\ ${ }^{2}$ Kayseri City Training and Research Hospital, Clinic of Cardiovascular Surgery, Kayseri, Turkey \\ ${ }^{3}$ Erciyes University Faculty and Medicine, Department of Internal Medicine, Intensive Care Unit, Kayseri, Turkey \\ ${ }^{4}$ Erciyes University Faculty and Medicine, Department of Cardiology, Kayseri, Turkey \\ ${ }^{5}$ Kayseri City Training and Research Hospital, Clinic of Hematology, Kayseri, Turkey
}

To the Editor,

There is not a large study in the literature other than a few case reports and reviews about the procedure of coronary artery bypass grafting surgery planned for patients with hemophilia. An internationally accepted definitive algorithm that recommends an approach to these patients was not included in the guidelines.

A 51-year-old male patient admitted in emergency service due to sudden and severe chest pain. He had no other medical history except hemophilia A. His electrocardiographic findings showed ST elevation in derivations II, III, and aVF. Troponin T at $0.19 \mathrm{ng} / \mathrm{mL}$ (normal: 0-0.1) was accepted as positive. The patient was admitted to the coronary intensive care unit with an initial diagnosis of acute inferior myocardial infarct and coronary angiography was urgently performed. Angiography revealed a moderate left ventricular ejection fraction (49\%) with three occluded coronary arteries. The left anterior descending artery was critically stenotic up to $80 \%$. The right coronary artery was stenotic up to 50\%. The circumflex coronary artery was also stenotic up to $90 \%$ (Figure 1). The patient received $50 \mathrm{U} / \mathrm{kg}$ (4000 U) factor VIII (FVIII) after angiography, which he was not able to receive before angiography due to the urgency of the case. Thereafter, he received $25 \mathrm{U} / \mathrm{kg}$ (2000) FVIII twice a day for 3 days, and then $20 \mathrm{U} / \mathrm{kg}(1600 \mathrm{U})$ FVIII was given for the following 7 days at intervals of $12 \mathrm{~h}$. No intervention was performed during angiography because of multi-vessel disease and bypass operation was decided. Among blood parameters tested during admission of the patient, the activated partial thromboplastin time (aPTT) was $51.4 \mathrm{~s}$. The FVIII inhibitor test was negative. His childhood FVIII level was 11.3; thus, he was evaluated as having a mild case of hemophilia A.

Prior to the bypass operation, the patient received $50 \mathrm{U} / \mathrm{kg}$ (4000 U) FVIII replacement and was taken to the operation with an aPTT value of $45.6 \mathrm{~s}$. The bypass operation was carried out with the same procedures as for non-hemophiliac patients including standard heparinization. In order to prevent disseminated intravascular coagulation during factor replacements of the patient, heparin was not used except for a pump procedure. After the patient was weaned from the cardiopulmonary pump, $50 \mathrm{U} / \mathrm{kg}(4000 \mathrm{U})$ bolus FVIII was administered. For the following 3 days, $25 \mathrm{U} / \mathrm{kg}(2000 \mathrm{U}) \mathrm{FVIII}$ was administered at intervals of $12 \mathrm{~h}$. Thereafter, $20 \mathrm{U} / \mathrm{kg}(1600 \mathrm{U})$ FVIII was administered for 7 days at intervals of $12 \mathrm{~h}$ (Table 1). The patient has been followed for 3 years with routine controls. Within this period, he has had no serious medical problems except nosebleeds.

When the literature was analyzed, it was identified that continued infusion of FVIII was rarely administered in pre- 


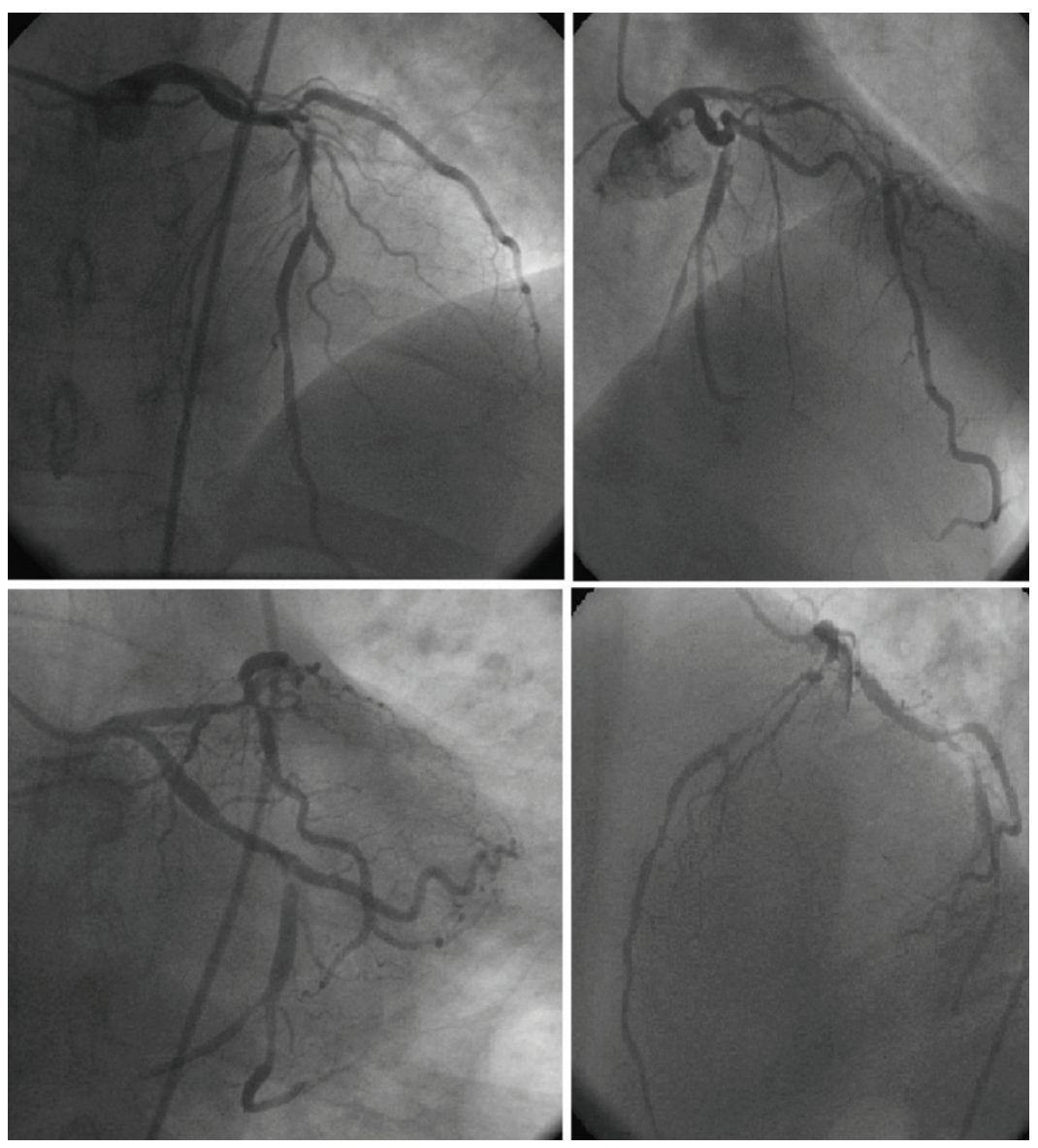

Figure 1. Stenosis: right coronary artery, 50\%; left anterior descending artery, 80\%; and circumflex coronary artery, 90\%.

\begin{tabular}{|c|c|c|c|}
\hline \multicolumn{4}{|c|}{$\begin{array}{l}\text { Table 1. Daily total dosage of factor VIII and evaluation of } \\
\text { activated partial thromboplastin time and factor VIII during } \\
\text { the perioperative period. }\end{array}$} \\
\hline Day & aPTT & FVIII & $\begin{array}{l}\text { FVIII dosage } \\
\text { (daily) }\end{array}$ \\
\hline 0 (angiography) & 51.4 & & $1 \times 4000 \mathrm{U}$ \\
\hline $1-3$ & - & - & $2 \times 2000 \mathrm{U}$ \\
\hline 4 & 49.1 & 14.5 & $2 \times 1600 \mathrm{U}$ \\
\hline $5-10$ & - & - & $2 \times 1600 \mathrm{U}$ \\
\hline \multicolumn{4}{|c|}{ Operation decision and surgery preparations } \\
\hline 25 (bypass) & 45.6 & & $2 \times 4000 \mathrm{U}$ \\
\hline $26-28$ & - & - & $2 \times 2000 \mathrm{U}$ \\
\hline 29 & 40.5 & 29.8 & $2 \times 1600 \mathrm{U}$ \\
\hline $30-35$ & - & - & $2 \times 1600 \mathrm{U}$ \\
\hline \multicolumn{4}{|c|}{ Exit from intensive care } \\
\hline 36 (nosebleed) & 39.9 & - & $2 \times 2000 \mathrm{U}$ \\
\hline 37 & 35.5 & - & $2 \times 2000 \mathrm{U}$ \\
\hline 38 & 34.0 & - & $2 \times 2000 \mathrm{U}$ \\
\hline \multicolumn{4}{|c|}{ Discharge preparations and warnings } \\
\hline 39 & 33.1 & - & None \\
\hline 40 & 33.4 & - & None \\
\hline 41 (discharge) & 36.1 & 53.7 & None \\
\hline
\end{tabular}

and intraoperative periods $[1,2]$. Similar to the literature, we did not administer continued infusion of FVIII because we believed that thrombosis risk was more of an issue compared to the bleeding.

The World Hemophilia Federation recommends FVIII levels between $80 \%$ and $100 \%$ before and after major operations [3], but considering the urgency and thrombosis risk in our case we brought a different approach, addressing all disciplines responsible for the case and arriving at a consensus. We present our method in Table 1 as a recommendation. In this method, we administered $2 \times 50 \mathrm{U} / \mathrm{kg}$ on the day of the operation ( 1 day), $2 \times 25 \mathrm{U} / \mathrm{kg}$ for the following 3 days, and $2 \times 20 \mathrm{U} / \mathrm{kg}$ for the following 7 days and we named it the "13-7 protocol". Our protocol needs to be tested with further studies.

Keywords: Hemophilia A, Coronary artery bypass surgery, Intermittent factor VIII administration

Anahtar Sözcükler: Hemofili A, Koroner arter bypass operasyonu, Aralıklı faktör VIII uygulaması

Informed Consent: Received. 
Conflict of Interest: The authors of this paper have no conflicts of interest, including specific financial interests, relationships, and/or affiliations relevant to the subject matter or materials included.

\section{References}

1. Kypson AP, Rodriguez E, Anderson CA. Coronary surgery in a hemophiliac with continuous factor VIII replacement. Asian Cardiovasc Thorac Ann 2012;20:191-192.
2. Shalabi A, Spiegelstein D, Lipey A, Kassif Y, Misgav M, Kogan A, Raanani E. Cardiac surgery in patients with hemophilia A and B. In: 62nd Annual Conference of the Israel Heart Society; Tel Aviv, Israel; 13-14 April 2015.

3. Srivastava A, Brewer AK, Mauser-Bunschoten EP, Key NS, Kitchen S, Llinas A, Ludlam CA, Mahlangu JN, Mulder K, Poon MC, Street A; Treatment Guidelines Working Group on Behalf of the World Federation of Hemophilia. Guidelines for the management of hemophilia. Haemophilia 2013;19:1-47.

\section{Prospective Evaluation of Non-Compliant Severe Hemophilia Patients}

Tedaviye Uyumsuz Ağır Hemofili Hastalarının Prospektif Değerlendirilmesi

(D) Mehmet Can Uğur1, (D) Kaan Kavaklı2

1 University of Health Sciences, Izmir Bozyaka Training and Research Hospital, Clinic of Hematology, Izmir, Turkey

${ }^{2}$ Ege University Faculty of Medicine, Department of Pediatric Hematology, Izmir, Turkey

To the Editor,

Patient compliance with the determined treatment regimen is a current issue in the treatment of hemophilia, and there are many studies that report compliance issues in patients with hemophilia $[1,2]$.

In our study, we applied a survey to 40 patients who participated in the adolescent workshop of Hemophilia Federation in March 2017, and we monitored 16 adolescent patients with severe hemophilia and investigated the changes in their compliance rates during a 1-year period. The survey was applied using face-to-face method. Subjects who were found to be non-compliant (patients who neglect to apply prophylaxis as recommended by their physicians) were monitored for 1 year. These subjects were reached by phone in months 6 and 12. The scope of these telephone calls was as follows: whether the subject was currently on prophylaxis, whether they were complying with the treatment plan, and the reasons for non-compliance.

This survey was an activity initiated for patients during a routine workshop. Therefore, we did not apply for ethics committee approval.
There were a total of 40 subjects: thirty nine patients with severe hemophilia and 1 patient with von Willebrand disease (vWD). Among these subjects, 16 were found to be noncompliant: twelve patients with hemophilia $A, 3$ patients with hemophilia $B$, and 1 patient with vWD. The average age of these 16 subjects was 21.25 years. Ten patients $(62.5 \%)$ were receiving prophylaxis. Two of the patients were middle school, 11 were high school, and 3 were university graduates.

There were 10 patients who were receiving prophylaxis at the start of study. The number of patients on prophylaxis increased to 12 and 14 at 6 and 12 months of follow-up. The rate of compliant patients was $43.75 \%$ in the sixth month and $56.25 \%$ in the first year.

It was determined that there were three reasons for noncompliance with the treatment: time constraints, being tired of the treatment, and problems with vascular access. The number of patients reporting these problems is presented in Table 1 .

The definition of "acceptable compliance" can greatly different between studies. Generally, if patients administer at least 75\% to $80 \%$ of the recommended doses, they are accepted to have perfect compliance [3]. Sixteen subjects who were found to be 